\title{
Sustainable debt policies despite the crisis? Empirical evidence for Iberian economies
}

\author{
Bettina Fincke
}




\title{
Sustainable debt policies despite the crisis? Empirical evidence for Iberian economies
}

\author{
Bettina Fincke*
}

February 2013 (revised in August 2013)

\begin{abstract}
This paper studies for the two major Iberian economies, Portugal and Spain, whether they pursue sustainable debt policies based on Bohn (1998)'s idea of a fiscal response mechanism. After presentation and discussion of theoretical reflections on the governmental budget, the empirical estimations are implemented with splines. By accounting for time-varying coefficients it is possible to detect how the fiscal response has been modified or developed over time. The outcome indicates sustainable fiscal behavior based on past observations of about the last 30 years for Portugal and Spain. However, the administration's response to increasing debt ratios has weakened over the years in Portugal and, recently, also in Spain.
\end{abstract}

JEL: H63, E62

Keywords: Public debt, Fiscal Sustainability, Time-Varying Parameters

Parts of these ideas were presented at NIFIP's Conference 'The present economic and sovereign debt crisis: evaluation and the way-out' in Porto, December 2012 as well as at UECE's Conference 'Economic and Financial Adjustments in Europe' ISEG/UTL, Lisbon, June 2013 and at SPERI's Annual Conference: 'Beyond Austerity vs. Growth-The future of the European Political Economy' Sheffield University, July 2013. Thanks is entitled to the conference participants. Especially I thank Gilles Dufrénot, Uwe Haskamp and Peter Claeys for their remarks.

${ }^{*}$ Department of Business Administration and Economics, Bielefeld University, P.O. Box 100131, 33501 Bielefeld, Germany, E-mail: bfincke@wiwi.uni-bielefeld.de 


\section{Introduction}

Europe - and many other parts of the world - has been hit hard by the financial and debt crisis and for over four years now the economic downswing with high unemployment, persistent budget deficits and rising public debt ratios troubles the affected economies. This concerns central European countries, like Germany and France, but also economies on the periphery, like Portugal, Ireland, Italy or Spain. The situation is especially severe in Greece: faced with huge deficits and imminent financial problems, a first 'rescue program' was organized for the Greek economy in spring 2010. It was financed mainly bilateral, including also IMF support, and covered 110 billion Euros. ${ }^{1}$ Aware of the serious difficulties, the European governments and institutions, namely the especially the European Central Bank (ECB) and the European Commission, agreed upon organization of instruments such as the European Financial Stabilization Mechanism (EFSM), the European Financial Stability Facility (EFSF) and the European Stability Mechanism (ESM). In return for the financial assistance packages the beneficiaries have to agree to implement rigid austerity programs. Midway through this unpleasant situation are also Portugal and Spain. Both applied for financial assistance, Portugal in spring 2011 and Spain in summer 2012 with regards to its banking sector.

Despite the current crisis, even under 'normal' conditions sound fiscal performance is an important aspect. This especially holds true for monetary union members, such as Euro zone economies in Europe with the European Monetary Union (EMU) for instance, as they commit to one single monetary policy. Concerning Europe this relevance has been recognized by Article 121 of European Union (1997)'s Consolidated Version of the Treaty on European Union, which requires "the sustainability of the government financial position". ${ }^{2}$ Therefore, the central research question of this paper considers whether a sustainable fiscal policy can actually be found based on empirical evidence for the Iberian economies.

In fact the Iberian Peninsula consists of the four states of Andorra, Gibraltar (British territory), Portugal and Spain - however, the focus of this analysis is set on the two main economies Portugal and Spain since they represent the majority share of Iberia's economic power. For instance, in 2008 Spain contributed $86.1 \%$ and Portugal $13.6 \%$ to the GDP of the Iberian Peninsula, while

$1 \quad$ By now, a second package of 130 billions Euros is bundled.

2 Cf. also Fincke (2012, ch. 1). 
Andorra's share was only $0.2 \%$ and Gibraltar's of about $0.1 \%{ }^{3}$ Within the European context the latter numbers even diminish, therefore this fiscal sustainability analysis concentrates on the Spanish and Portuguese economies.

A good impression of the recent economic situation and evolution - concerning the public finance perspective - can be gained by studying the interest rate spread development of Portugal and Spain. Here, the difference is based on calculations of the long-run government bond yield of the two Iberian economies compared to Germany. ${ }^{4}$

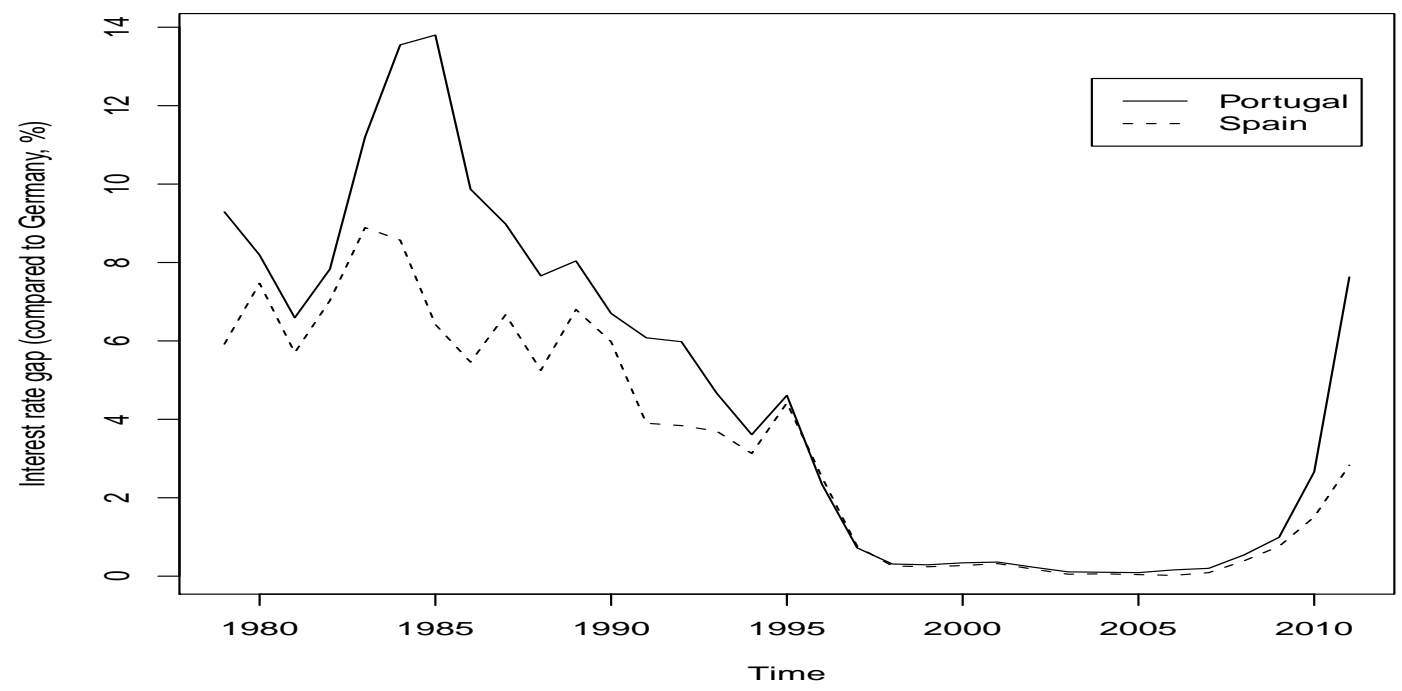

Figure 1: Iberian interest rates compared to German bonds (1979-2011) in \%.

Obviously, both economies profited from the proceeding European integration, both entered the EU in 1986, and the preparation of a common currency, with enforced sound fiscal performance, in terms of decreasing interest rates (compared to central European economies). This situation lasted for about the years of the 2000s, until, with the outbreak of the crisis the gaps started to widen again. This development distinctly displays the dynamics of the economics of European integration and accounts for volatility, here, for the Iberian economies.

While sustainability itself is an old concept rooted in forestry sciences, indeed exactly 300 years old this year if Von Carlowitz (2000)'s '...nachhaltende Nutzung...' [in English: sustainable usage] is the reference, ${ }^{5}$ Burger $(2003,2005)$ claims that also the idea of the solvency of an economy 3 See Worldbank (2013) and Government of Gibraltar (2013) for the data. Numbers have been converted to US \$.

4 Cf. International Monetary Fund (2013) for the data, author's calculations. All estimations and plots have been implemented in R 2.9.0.

5 Cf. for instance Pittel (2002) or Grober (2007). 
or state has been existing for a long time, even though the term fiscal sustainability arose in the 1970s to 1980s. As regards central empirical literature contributions to fiscal or debt sustainability, certainly the seminal paper of Hamilton and Flavin (1986), who employ time series analysis, matters. Also Hakkio and Rush (1991)'s approach is of relevance, which studies the development of public revenues and expenditures and tests for cointegration. Moreover, Trehan and Walsh (1991) introduce a unit root approach considering the budget deficit. Furthermore, Bohn (1998) presents a test that is less dependent on interest rate assumptions and concentrates on the reaction of the primary surplus to changes in public debt, both relative to GDP. For a more detailed survey on applications of fiscal sustainability tests for Euro area members see Afonso (2005) or a more recent study by Afonso and Jalles (2012) for instance. Also, a more comprehensive discussion on the terminology and the literature approaches can be found in Fincke (2012, ch. 2).

Regarding other debt sustainability contributions on Iberian economies, a recent paper by Haskamp (2013) for instance finds empirical evidence for a sustainable fiscal policy in Spain, while for Portugal many studies suggest that its fiscal policy might not be characterized by sustainability or give mixed results, see Afonso (2005) or Marinheiro (2006) for example.

This paper studies the fiscal policy behavior of Portugal and Spain and whether it may be considered sustainable. The analysis especially focuses on Bohn (1998)'s fiscal response mechanism while also discussing country specific characteristics by utilizing time-varying coefficients in order to detect those circumstances. Concerning the technique splines regression is performed. The remainder is organized as follows: section 2 briefly introduces the central theoretical concepts and section 3, first, introduces the methodology and, then, presents the empirical outcomes. Finally, section 4 summarizes the main results and concludes this paper.

\section{Theoretical background}

From a traditional public finance perspective a government usually decides on its public responsibilities - normally in a democratic way - which provides knowledge about the (expected) expenditures that come along with fulfilling them. Then, the administration has the duty to raise revenues in order to finance these disbursements. ${ }^{6}$ This signifies, however, that any government has to obey a central economic concept: balancing budgets. Therefore, in order to finance

$6 \quad$ Even though recent studies indicate that there is empirical evidence that the revenue volume may determine the spending, see for instance Afonso and Jalles (2012). 
the primary expenditures, $G$, the government has to generate taxes, $T$, of (at least) the same amount. In case the latter are not sufficiently high enough, the government may issue bonds, $B$, with the purpose to fill the liquidity gap (i.e. deficits, $D E F$ ), this however also means that, once the country is a debtor, a new type of expenditures must be taken into account: interest payments, $r B$. Thus, the governmental budget can be expressed by the subsequent equation: ${ }^{7}$

$$
\frac{d B(t)}{d t}=G(t)-T(t)+r(t) B(t)=-S(t)+r(t) B(t)
$$

with $t$ indicating time and the primary surplus, $S$, consists of $S(t)=T(t)-G(t)$. The solution of equation (1) - in present value terms - leads to the following two central conditions concerning public debt sustainability: ${ }^{8}$

$$
B(0)=\int_{0}^{\infty} e^{-\int_{0}^{\mu} r(\phi) d \phi} S(\mu) d \mu \quad \Leftrightarrow \quad \lim _{t \rightarrow \infty} B(t) e^{-\int_{0}^{t} r(\mu) d \mu}=0 .
$$

The first part of (2), the present value borrowing constraint, expresses that the present value of upcoming primary surpluses must be equal to the initially existing amount of public debt, i.e. in $t=0$. Strictly speaking it's expected primary surplus values. The second condition in (2), the No-Ponzi-Game condition, signifies that asymptotically the present value of public debt must converge to zero. A governmental debt policy that fulfils these requirements can be considered sustainable, cf. also Greiner et al. (2007, p. 197).

Now, taking Bohn (1998)'s idea into account, which principally states that the primary surplus to GDP ratio $(s)$ is in a way determined by the debt to GDP ratio $(b)$, gives:

$$
s(t)=\theta b(t)+\omega
$$

with $\theta$, the parameter of interest, reflecting the reaction of the primary surplus ratio to variations in debt ratio and the constant $\omega$ expressing all other effects, both $\theta, \omega \in \mathbb{R}$. Combining Bohn (1998)'s idea with the governmental budget (1) from above, shows that a significant and positive reaction coefficient $\theta$ indicates sustainability - under certain conditions, see for instance Greiner et al. (2007). Further, if equation (1) is expressed in terms of ratios to GDP, $Y$, such a combination yields:

$$
\frac{d\left(\frac{B(t)}{Y(t)}\right)}{d t}=(r(t)-\gamma(t)-\theta) b(t)-\omega
$$

with $\gamma$ denoting the GDP growth rate. Solving (4) for the public debt ratio indicates a more precise sustainability measure. Assuming a positive difference between the interest rate and

$\overline{7} \quad$ Cf. for instance Greiner et al. (2007) for these calculations. The notation refers to continuous and real variables.

8 For a more detailed solution cf. Fincke (2012, ch. 3.1). 
the economic growth rate, $\bar{r}-\bar{\gamma}>0$, here simplified to averages, ${ }^{9}$ the public debt ratio will asymptotically only remain bounded, i.e. converge to zero or stay constant for $t \rightarrow \infty$, if the reaction coefficient $\theta$ exceeds the positive average interest rate-growth rate gap, $\bar{r}-\bar{\gamma}$. For these reflections a finite constant upper value for $\omega$ is assumed, i.e. $|\omega|<\infty$, which is economically reasonable since it reflects (all other) effects on the primary surplus ratio. See Fincke (2012) or Fincke and Greiner (2011) for a more detailed analysis. Thus, the central aspect to test for sustainability addresses $\theta$.

Therefore, in order to assess sustainability a positive reaction coefficient is relevant as well as the difference between the interest rate and the growth rate. But despite the convenience, the approach does not come without shortages. For instance, there is a natural limit to Bohn (1998)'s reaction mechanism: since $S$ is financed out of GDP, $s$ cannot be increased without limit. Once that level has been reached the response test may not work anymore, see Fincke and Greiner (2011) for a profound argumentation. Finally, temporarily a country may well pursue a sustainable fiscal policy despite a rising debt ratio, this simply indicates that the positive reaction has not been strong enough to stabilize the debt ratio. Certainly, sooner or later the debt ratio should stabilize.

Nevertheless, Bohn's approach is a strong test and used in the following section to study whether the Portuguese and Spanish economies implemented a sustainable fiscal policy.

\section{Empirics}

In order to assess fiscal sustainability according to Bohn (1998)'s approach, i.e. the relationship between the primary surplus ratio and the public debt ratio, first, the relevant assumptions have to be checked and some explanations on the dataset provide insight on the data structure. Then, a short introduction to the estimation technique is given in section 3.1 and, finally, section 3.2 presents the test results.

Regarding the essential assumption on the interest rate and growth rate gap, the following table 1 summarizes the past empirical observations for Portugal and Spain respectively. ${ }^{10}$

Accordingly, this difference is at least positive on average from the middle of the 1980s onwards.

$9 \quad$ For Iberia this assumption is also empirically reasonable as outlined in chapter 3.

10 See OECD (2013) and International Monetary Fund (2013) for the data, author's calculations. 


\begin{tabular}{c|c|c}
\multicolumn{2}{c}{$(\bar{r}-\bar{\gamma})$ in \% } \\
& $1985-2011$ & $1990-2011$ \\
\hline Portugal & 0.088 & 1.204 \\
Spain & 0.521 & 0.541 \\
\hline
\end{tabular}

Table 1: Interest rate and growth rate gap for Portugal and Spain.

Therefore, the central precondition seems to be fulfilled empirically and the approach is applicable to the Portuguese and Spanish fiscal policy situation.

The dataset is mainly based on OECD (2013). Regarding the demarcation of the public sector the general government classification is used here, meaning all subordinated administrative levels and the social security system are included. Public debt is measured as gross financial liabilities, not taking assets into account. Only for the long run interest rate International Monetary Fund (2013)'s data, i.e. bond yields, are used, which are also the basis for the spread or gap calculation in order to capture the volatility and reflect the dynamics of European integration and the crisis development. All data are measured in annual frequency.

The next section briefly introduces the methodology of spline estimation and the merits of timevarying coefficients.

\subsection{Methodology}

For estimating the relationship between two - or eventually more - empirical variables regression analysis models are the most common approach, mainly performed in a parametric manner, i.e. OLS. A more flexible estimation technique with fewer assumptions can for instance be implemented by utilizing splines. They basically describe the systematic link between the variables by a flexible function, which is only required to be continuous and appropriately differentiable. For an introduction see for example Ruppert et al. (2003), Keele (2008), Kauermann (2006) or Greiner (2009).

Applied to the research questions of this paper, the relationship between the dependent variable, the primary surplus ratio $s$, and the explanatory variable, public debt ratio $b$, for both Iberian economies is to be estimated. The following graphics illustrate the initial situation for both 
countries: Portugal (1978-2011, solid lines), and Spain (1980-2011, dashed lines). ${ }^{11}$

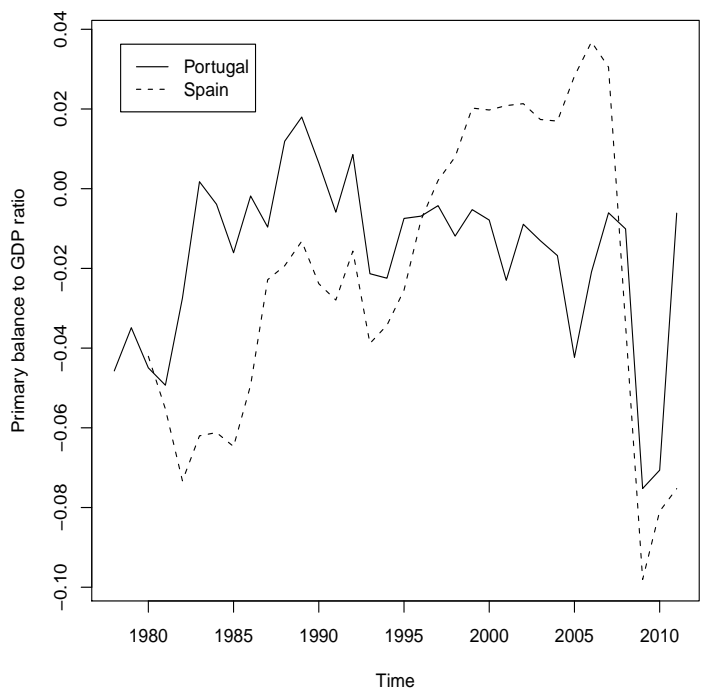

Figure 2: Primary surplus to GDP ratio for Portugal and Spain.

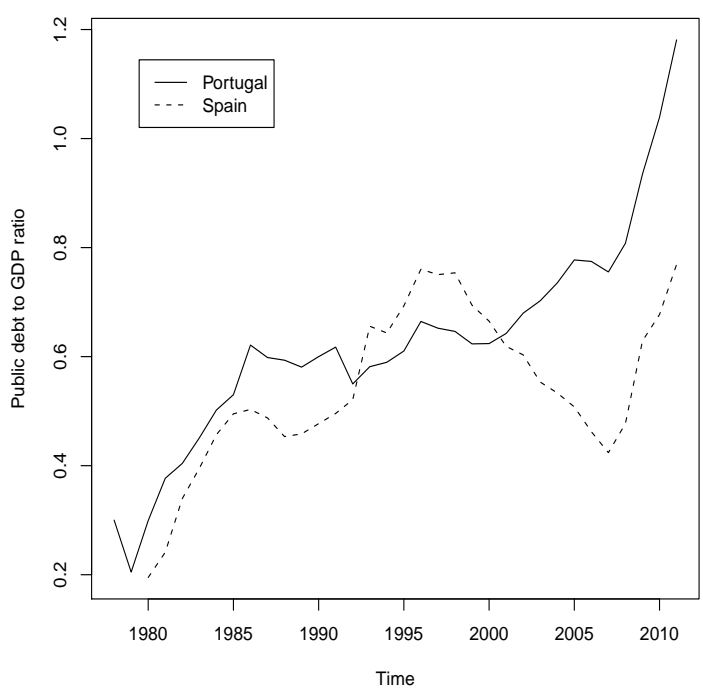

Figure 3: Debt to GDP ratio for Portugal and Spain.

Concentrating on the Spanish case for illustrative reasons, the subsequent plot 4 presents the central relationship between the primary surplus and debt, both relative to GDP. ${ }^{12}$

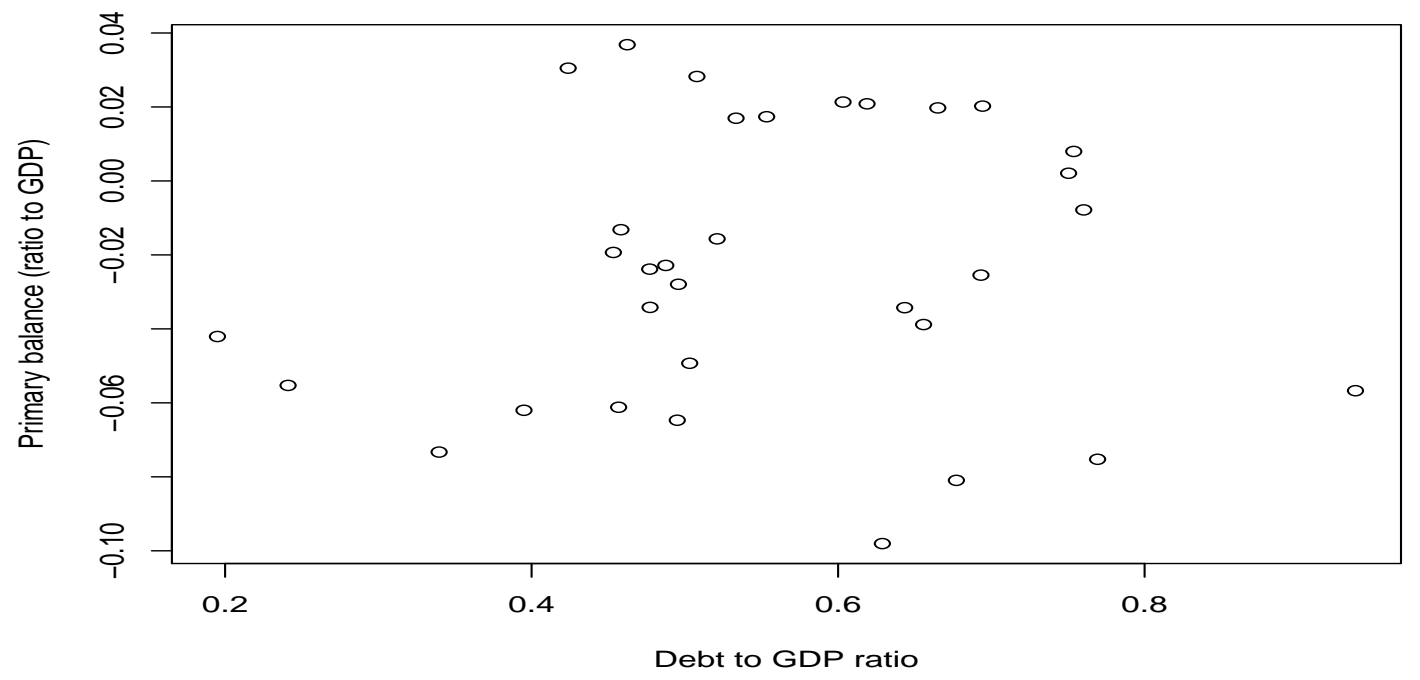

Figure 4: Primary surplus and debt to GDP ratio for Spain (1980-2012).

Obviously, no clear pattern is observable. The observations are mainly clustered around $60 \%$ debt ratio with varying primary balances. Maybe, another explanatory variable modifies this original relationship. Since Spain is an EMU economy, which has been shaped by European $11 \quad$ Cf. OECD (2013) for the data.

12 Here the series has been extended to 2012 in order to include an additional crisis observation. 
integration and recently by the crisis, as already visualized by the spreads in figure 1 , an evidently modifying variable is 'time'. Thus, figure 5 shows the primary surplus to GDP ratio relationship from above conditioned on time. Here, decades have been chosen with the last plot containing the crisis observations.
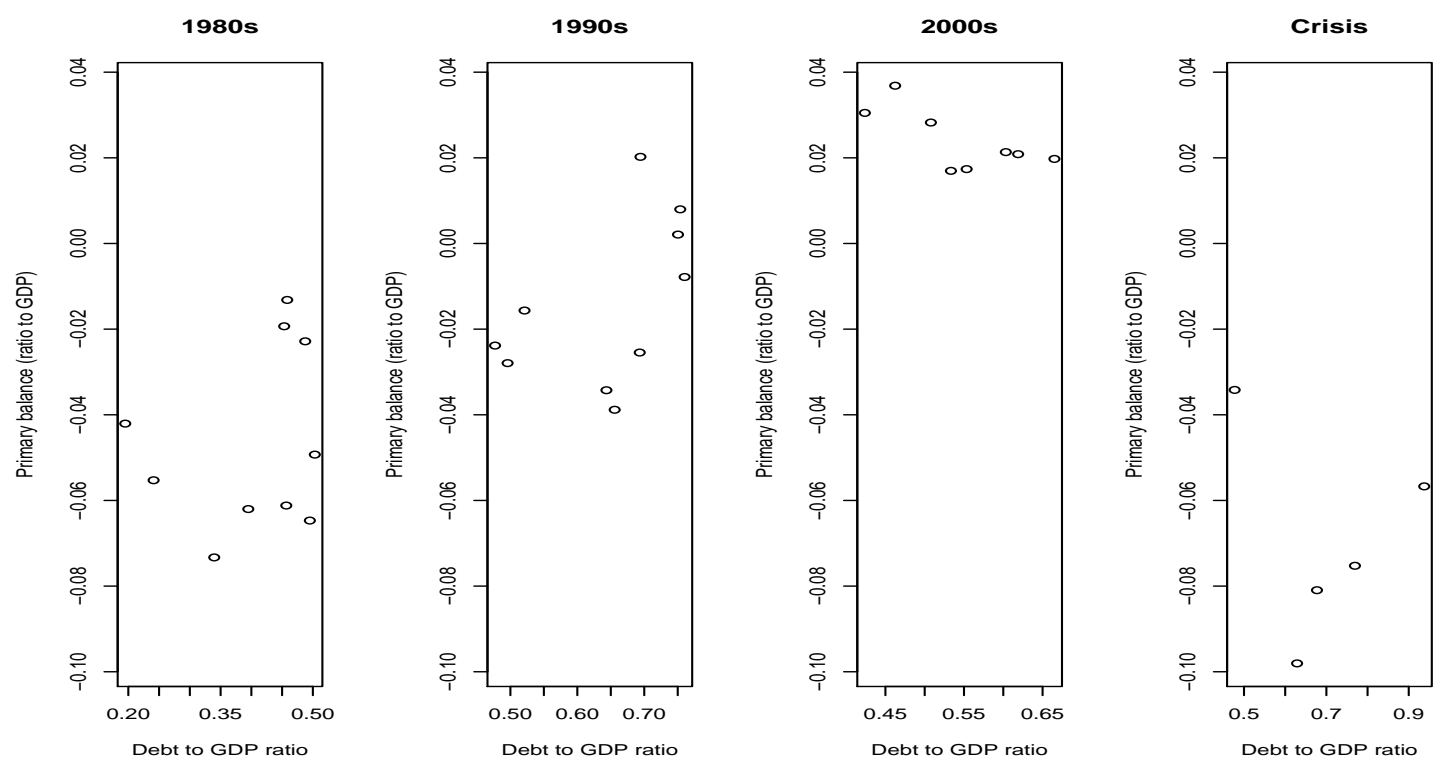

Figure 5: Primary surplus and debt ratio for Spain (1980-2012) separated by decades.

Apparently, the relationship between the Spanish primary surplus ratio and its debt ratio changes over the years. While there is an increasing pattern in the 1980s and 1990s (enforcing a sound fiscal position), stabilization can be observed in the 2000s with primary balances around $2.5 \%$ and debt ratio values around $55 \%$ - before the situation is plummeting due to the crisis. ${ }^{13}$

Accordingly, an appropriate regression equation to capture this type of relationship is:

$$
s=f(t) b+\epsilon,
$$

with $\epsilon$ for the errors, being i.i.d $N\left(0, \sigma^{2}\right)$. Including additional control variables the full estimation model is described by:

$$
s(t)=\omega_{0}+\theta(t) b(t-1)+\omega_{1} Y G a p(t)+\omega_{2} G G a p(t)+\epsilon(t),
$$

estimated separately for each economy. To account for business cycle influences, an output gap YGap has been included, with the trend being obtained from the Hodrick-Prescott filter. Similarly, an expenditure gap GGap has been included, with $G G$ expressing the overall outlays of the government.

13 Cf. also Fincke (2012, sec. 4.1.1) for a similar methodology motivation. 


\subsection{Estimation results}

Using the Iberian data to estimate the fiscal response mechanism according to Bohn (1998), this chapter presents the outcome of the spline estimation of equation (6). Regarding the sign of the coefficients, a positive reaction coefficient is expected for the debt ratio corresponding to the theoretical reflections from above. For the business cycle variable YGap a positive sign indicates counter-cyclical policy behavior and for the expenditure gap GGap a negative sign can be expected, meaning in times of higher spending than usual, the primary balance ratio will be affected negatively. Separate estimations of the regression equation (6) for Portugal (1978-2011) and Spain (1980-2011) yield the following results: ${ }^{14}$

\begin{tabular}{c|ccc} 
& Coeff. & $\begin{array}{c}\text { Std. error } \& \\
\text { (t-stat) }\end{array}$ & $\operatorname{Pr}(>\mathbf{t})$ \\
\hline Const. & -0.09 & $0.015(-5.76)$ & $3.35 \cdot 10^{-6}$ \\
$b(t-1)$ & 0.13 & $0.027(4.77)$ & $5.05 \cdot 10^{-5}$ \\
YGap $(t)$ & 0.30 & $0.096(3.13)$ & 0.004 \\
$\operatorname{GGap}(t)$ & -0.23 & $0.069(-3.29)$ & 0.003 \\
\hline $\operatorname{sm}(\mathrm{t})$ & edf & $\mathrm{F}$ & $\mathrm{p}-\mathrm{val}$. \\
by $b(t-1)$ & 1.67 & 9.3 & $6.43 \cdot 10^{-5}$ \\
\hline & $R^{2}(\operatorname{adj}): 0.60$ & DW: 1.70
\end{tabular}

Table 2: Estimation results Portugal.

\begin{tabular}{c|ccc} 
& Coeff. & $\begin{array}{c}\text { Std. error \& } \\
\text { (t-stat) }\end{array}$ & $\operatorname{Pr}(>\mathbf{t})$ \\
\hline Const. & -0.09 & $0.022(-4.24)$ & 0.0003 \\
$b(t-1)$ & 0.14 & $0.046(2.93)$ & 0.008 \\
$Y G a p(t)$ & 0.75 & $0.149(4.99)$ & $5.1 \cdot 10^{-5}$ \\
$\operatorname{GGap}(t)$ & -0.35 & $0.081(-4.25)$ & 0.0003 \\
\hline $\operatorname{sm}(\mathrm{t})$ & edf & $\mathrm{F}$ & $\mathrm{p}-\mathrm{val}$. \\
by $b(t-1)$ & 5.54 & 8.1 & $2.91 \cdot 10^{-5}$ \\
\hline & $R^{2}(\mathrm{adj}): 0.92$ & DW: 1.66
\end{tabular}

Table 3: Estimation results Spain.

The results show a significantly positive reaction coefficient, indicating sustainable debt policies, for both, Portugal and Spain. Moreover, the remaining parameters show the expected signs and are statistically significant. For Spain the business cycle parameter shows a relatively strong effect. The diagnostics suggest a fair fit of the model. ${ }^{15}$ The interesting part is the time-dependent smooth term, sm, which is also statistically significant and indicates changes in the fiscal behavior over time. The plots of these deviations are depicted in figures 6 and 7 below. Please note, the plots are centered around the average value - thus, zero in the figures corresponds to the reaction coefficient values of table 2 and 3 respectively.

For Portugal, the graph shows a constantly decreasing shape. Economically, this run displays a declining emphasis of the Portuguese government on debt stabilization. Meaning, despite a positive reaction coefficient, the lack of the administration's willingness or ability to put more effort on correcting the trend resulted in the increasing debt ratio, which

14 See OECD (2013) for the data. Initially, the regressions also included the interest rate gap, which however didn't yield significant effects for all estimations. Thus, it has been neglected in order to present consistent and comparable results. The estimations were performed with $m g c v$ in $\mathrm{R}$ 2.5.0. 


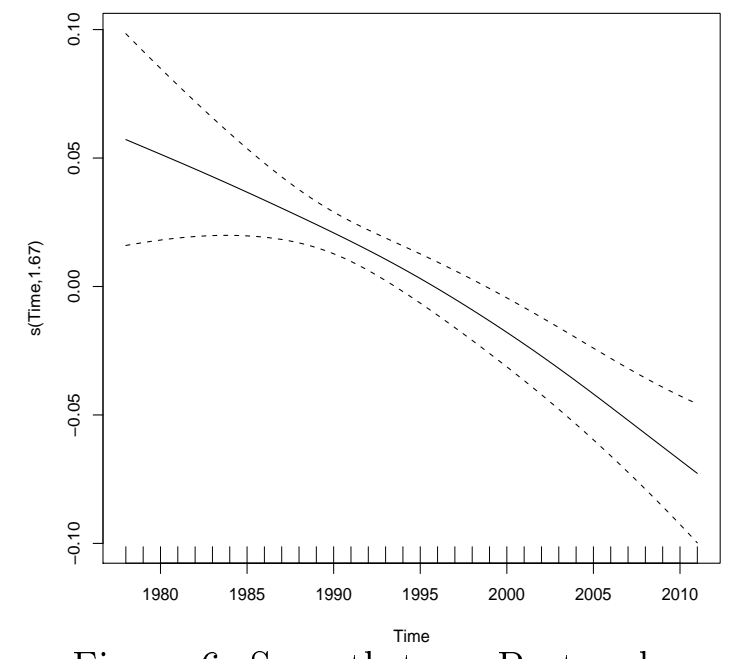

Figure 6: Smooth term Portugal.

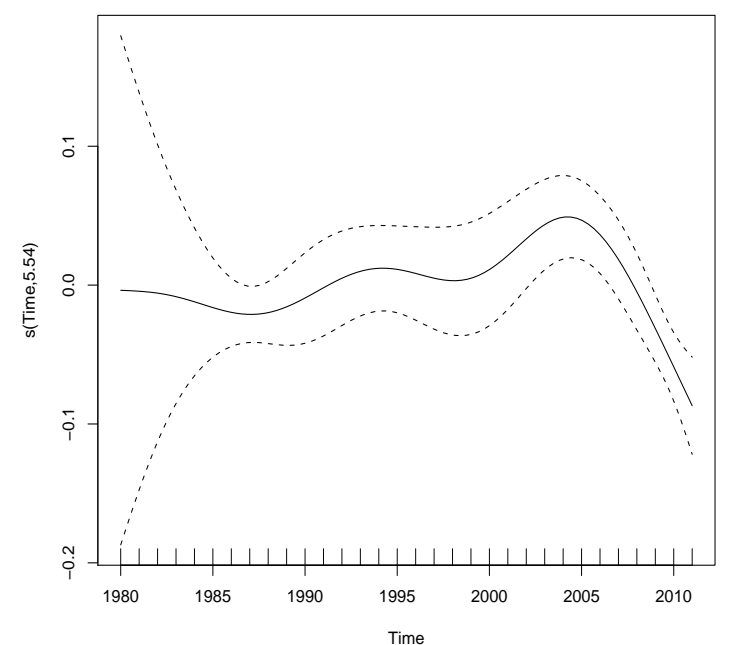

Figure 7: Smooth term Spain.

has been illustrated in figure 3. Thus, this development plus facing the crisis finally helps to partially explain Portugal's application for financial assistance in 2011.

Corresponding to the decomposition by decades in figure 5, figure 7 now mainly displays the reaction coefficient development over time: a more or less increasing trend until the middle of the 2000s, which turns around afterwards and deteriorates with the crisis years. Obviously, the time-varying coefficient estimation presents a good approximation of the underlying relationship.

However, a government's focus might not only aim at the debt policy and fiscal sustainability. Rather, the administration might also put emphasis on stabilization of the business cycle and try to find a balance between these two goals. ${ }^{16}$ Therefore, in a next step both of the variables, $b(t-1)$ and YGap, are included in the estimation of (6) as time-varying. Accordingly, $\omega_{1}$ becomes $\omega_{1}(t)$. Tables 4 and 5 present the outcomes. ${ }^{17}$

These estimation results confirm the significantly positive reaction coefficient for Portugal. For Spain it now turns out to be positive but not statistically significant. The other coefficients show the expected signs. Again, a distinctive influence on the primary balance seems to be the output gap, which is displayed by YGap. Here, once more the interesting feature is the development over time. The paths of both smooth terms are shown in

\footnotetext{
$16 \quad$ I thank Gilles Dufrénot for pointing this out.

17 Here the lagged dependent variable is included in order solve possible autocorrelation.
} 


\begin{tabular}{c|ccc} 
& Coeff. & $\begin{array}{c}\text { Std. error \& } \\
\text { (t-stat) }\end{array}$ & $\operatorname{Pr}(>\mathbf{t})$ \\
\hline Const. & -0.09 & $0.018(-4.80)$ & $5.49 \cdot 10^{-5}$ \\
$s(t-1)$ & -0.01 & $0.158(-0.07)$ & 0.944 \\
$b(t-1)$ & 0.13 & $0.030(4.20)$ & 0.0003 \\
$Y G a p(t)$ & 0.33 & $0.109(2.99)$ & 0.006 \\
$G G a p(t)$ & -0.21 & $0.074(-2.86)$ & 0.008 \\
\hline $\operatorname{sm}(\mathrm{t})$ & edf & $\mathrm{F}$ & $\mathrm{p}$-val. \\
by $b(t-1)$ & 1.58 & 5.72 & 0.0019 \\
by $Y G a p(t)$ & 1 & 0.54 & 0.4672 \\
\hline & $R^{2}(\mathrm{adj}): 0.58$ & $\mathrm{BG}: 7.70$
\end{tabular}

Table 4: Re-estimation results Portugal.

\begin{tabular}{c|ccc} 
& Coeff. & $\begin{array}{c}\text { Std. error \& } \\
\text { (t-stat) }\end{array}$ & $\operatorname{Pr}(>\mathbf{t})$ \\
\hline Const. & -0.05 & $0.029(-1.72)$ & 0.107 \\
$s(t-1)$ & -0.31 & $0.165(-1.86)$ & 0.084 \\
$b(t-1)$ & 0.01 & $0.067(0.15)$ & 0.881 \\
$Y G a p(t)$ & 0.59 & $0.165(3.59)$ & 0.003 \\
$G G a p(t)$ & -0.20 & $0.100(-1.98)$ & 0.068 \\
\hline $\operatorname{sm}(\mathrm{t})$ & edf & $\mathrm{F}$ & $\mathrm{p}-\mathrm{val}$. \\
by $b(t-1)$ & 6.17 & 13.8 & $1.73 \cdot 10^{-5}$ \\
by $Y G a p(t)$ & 6.97 & 6.7 & 0.0009 \\
\hline & $R^{2}(\operatorname{adj}): 0.98$ & BG: 2.85
\end{tabular}

Table 5: Re-estimation results Spain.

figures 8 to 11 for Spain and Portugal respectively.

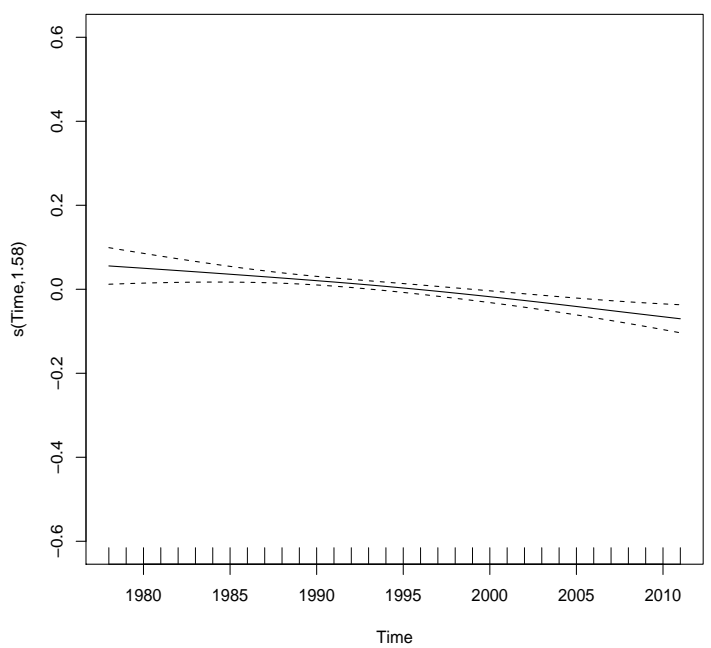

Figure 8: Smooth term of $b(t-1)$ for Portugal.

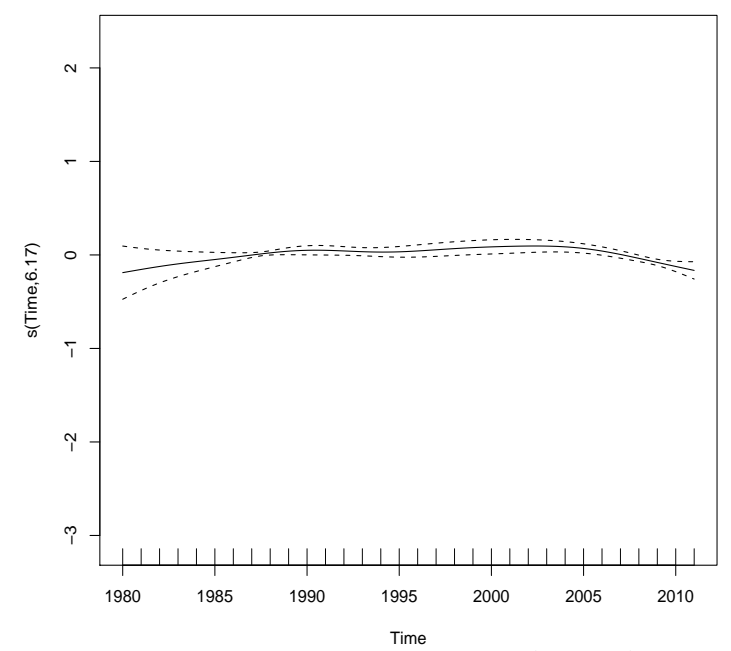

Figure 9: Smooth term of $b(t-1)$ for Spain.

Regarding the development over time, for the debt ratio behavior in figures 8 and 9 a similar shape as in figures 6 and 7 can be observed: for Portugal a slightly decreasing pattern is shown. For Spain there is a small increase towards the 2000s. For the newly included time-varying output gap effect, figures 10 and 11 reveal a linear increasing shape for Portugal, which however is not statistically significant, and for Spain a strong upward movement in the early 2000s. These features expose the GDP influence and may be interpreted as increasing emphasis on output performance. For Spain this was dominant in the 2000s before the recession and crisis hit the economy hard.

All in all, the tests suggest fiscal sustainability for Portugal and Spain despite the rising debt ratios based on the first estimation results. This outcome, however, does not state, that this situation is automatically given for the future. Moreover, the applications for fiscal programs of both countries underline this point: stronger fiscal effort is essential for 


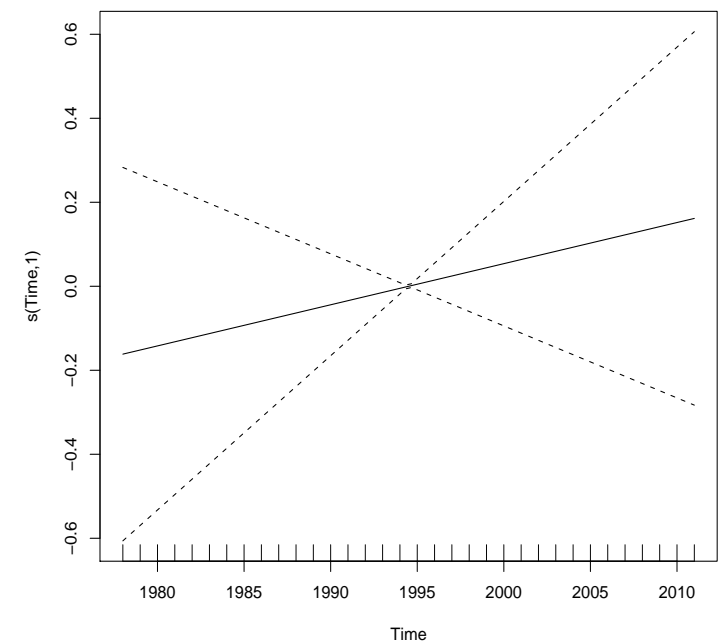

Figure 10: Smooth term of YGap for Portugal.

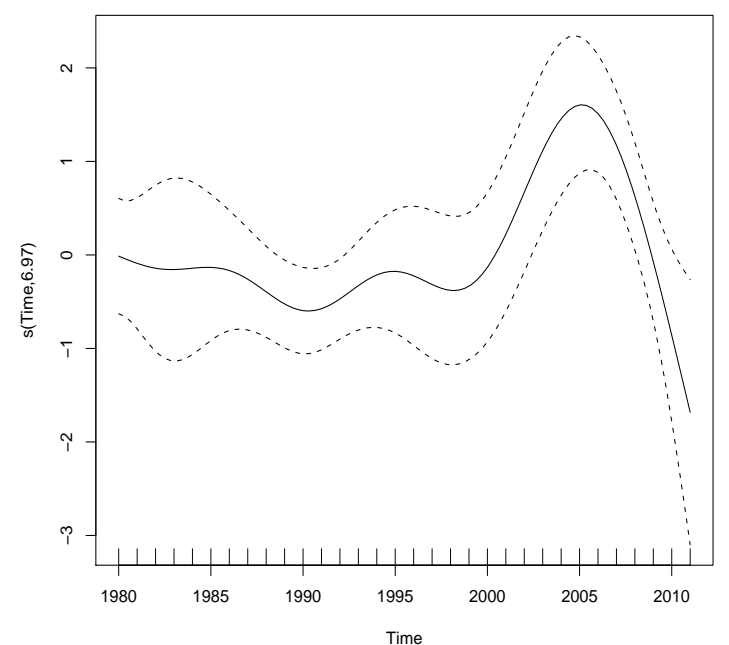

Figure 11: Smooth term of YGap for Spain.

turning around the negative trend of the response (as regards the debt ratio).

\section{Summary}

The analysis of this paper has studied sustainability of public debt according to Bohn (1998)'s fiscal response mechanism. Accordingly, a fiscal policy is regarded as sustainable once the primary balance relative to GDP is enhanced in response to increasing debt ratios - like a corrective activity. Subsequently, based on the theoretical background, the concept has been transferred to the empirical methods of spline estimations.

Such a sustainable fiscal behavior can be observed for both large Iberian economies, Portugal and Spain, based on country specific semi-parametric estimations allowing for time-varying parameters with data for about the last 30 years. However, the response has not been strong enough to turn the increasing trend of the debt ratio around. This also becomes clear in the development of the reaction (coefficient) over time: for both countries the response is languishing, especially severe recently with the proceeding of the crisis. Also, the data reveal an increasing emphasis on output stabilization over time or relevance of GDP performance. This effect is especially distinctive for Spain in the early 2000s. Returning to the initial research question on fiscal sustainability, as a result the Portuguese and Spanish administration should enhance their effort on debt stabilization. 


\section{References}

Afonso, A. (2005). Fiscal sustainability: the unpleasant European case. Finanzarchiv 61 (1), 19-44.

Afonso, A. and J. T. Jalles (2012). Revisiting Fiscal Sustainability Panel Cointegration and Structural Breaks in OECD Countries. European Central Bank Working Paper Series No. 1465.

Bohn, H. (1998). The behavior of U.S. public debt and deficits. The Quarterly Journal of Economics 113 (3), 949-963.

Burger, P. (2003). Sustainable Fiscal Policy and Economic Stability. Edward Elgar, Cheltenham.

Burger, P. (2005). Fiscal sustainability: the origin, development and nature of an ongoing 200-year old debate. Berichte aus dem Weltwirtschaftlichen Colloquium der Universität Bremen Nr. 98, 1-32, Universität Bremen.

Burger, P., I. Stuart, C. Jooste, and A. Cuevas (2011). Fiscal sustainability and the fiscal reaction function for South Africa. IMF Working Paper WP/11/69, 1-27, International Monetary Fund, Washington D.C.

European Union (1997). Consolidated Version of the Treaty on European Union (English ed.). Official Journal of the European Communities, C 340, 10. November 1997, access via: http://eur-lex.europa.eu/en/treaties/index.htm html version, last access June 1st, 2011.

Fincke, B. (2012). Public Debt Sustainability: From Roots to Regressions. PhD Thesis (Dissertationsschrift), Universität Bielefeld, Fakultät für Wirtschaftswissenschaften, Bielefeld, Germany.

Fincke, B. and A. Greiner (2011). Do large industrialized economies pursue sustainable debt policies? A comparative study for Japan, Germany and the United States. Japan and the World Economy 23 (3), 202-213.

Government of Gibraltar (2013). "Information Services, Statistics", Key Indicators, http://www.gibraltar.gov.gi/statistics, last access January 8th, 2013. 
Greiner, A. (2009). Estimating penalized spline regressions: theory and application to economics. Applied Economics Letters 16 (18), 1831-1835.

Greiner, A., U. Koeller, and W. Semmler (2007). Debt sustainability in the European Monetary Union: theory and empirical evidence for selected countries. Oxford Economic Papers 59 (2), 194-218.

Grober, U. (2007). Deep roots - A conceptual history of 'sustainable development' (Nachhaltigkeit), Access via: http://bibliothek .wzb.eu/pdf/2007/p07-002.pdf, last access September 20th, 2011. Environmental Policy - WZB-Discussion Papers, Wissenschaftszentrum Berlin für Sozialforschung (WZB) Best.-Nr. P 200\%-002, Berlin.

Hakkio, C. S. and M. Rush (1991). Is the budget deficit "too large?". Economic Inquiry 29 (3), 429-445.

Hamilton, J. D. and M. A. Flavin (1986). On the Limitations of Government Borrowing: A Framework for Empirical Testing. The American Economic Review 76 (4), 808-819.

Haskamp, U. (2013). Was Spanish fiscal policy sustainable? Empirica, published online, DOI $10.1007 / \mathrm{s} 10663-013-9211-5$.

International Monetary Fund (2013). International Statistical Yearbook, IMF's International Financial Statistics. via StatistikNetz.de, DSI Data Service 8 Information.

Kauermann, G. (2006). Nonparametric models and their estimation. Allgemeines Statistisches Archiv 90 (1), 137-152.

Keele, L. (2008). Semiparametric regression for the Social Sciences. Wiley \& Sons, Chichester.

Marinheiro, C. F. (2006). The sustainability of Portuguese fiscal policy from a historical perspective. Empirica 33, 155-179.

OECD (2013). OECD 'Economic Outlook Statistics and Projections' and 'Fiscal Positions and Business Cycles (historical ed.)' data. OECD Selection, via StatistikNetz.de, DSI Data Service \& Information.

Pittel, K. (2002). Sustainability and Endogenous Growth. New Horizons in Environmental Economics, Edward Elger, Cheltenham, UK. 
Ruppert, D., M. P. Wand, and R. J. Carroll (2003). Semiparametric Regression. Cambridge University Press, Cambridge.

Trehan, B. and C. E. Walsh (1991). Testing Intertemporal Budget Constraints: Theory and Applications to U.S. Federal Budget and Current Account Deficits. Journal of Money, Credit and Banking 23 (2), 206-223.

Von Carlowitz, H. C. (2000). Sylvicultura oeconomica, Anweisung zur wilden Baum-Zucht (Reprint der Ausg. Leipzig, Braun 1713 / bearb. von Klaus Irmer ed.). TU Bergakad. Freiberg, Univ.-Bibliothek "Georgius Agricola".

Worldbank (2013). Worldbank Selection Data. via StatistikNetz.de, DSI Data Service 6 Information. 


\section{A Appendix: Further estimation results}

The following tables show the estimation outcomes of (6) once the lagged dependent variable is included in the regression in order to resolve problems of possible autocorrelation. Economically this variable reflects 'inertial' behavior of the primary balance or the administration, see Burger et al. (2011) for instance. However, they turn out to be insignificant for both economies. Since the estimations include a lagged dependent variable, the Breusch-Godfrey test, $B G$, is used to check for autocorrelation.

\begin{tabular}{c|ccc} 
& Coeff. & $\begin{array}{c}\text { Std. error } \& \\
\text { (t-stat) }\end{array}$ & $\operatorname{Pr}(>\mathbf{t})$ \\
\hline Const. & -0.09 & $0.018(-4.82)$ & $4.82 \cdot 10^{-5}$ \\
$s(t-1)$ & 0.04 & $0.143(0.26)$ & 0.796 \\
$b(t-1)$ & 0.13 & $0.030(4.23)$ & 0.0002 \\
$Y G a p(t)$ & 0.30 & $0.099(2.97)$ & 0.006 \\
$G G a p(t)$ & -0.22 & $0.071(-3.15)$ & 0.004 \\
\hline $\operatorname{sm}(\mathrm{t})$ & edf & $\mathrm{F}$ & $\mathrm{p}$-val. \\
by $b(t-1)$ & 1.56 & 5.66 & 0.0019 \\
\hline & $R^{2}(\operatorname{adj}): 0.58$ & BG: 7.70
\end{tabular}

Table 6: Estimation results Portugal.

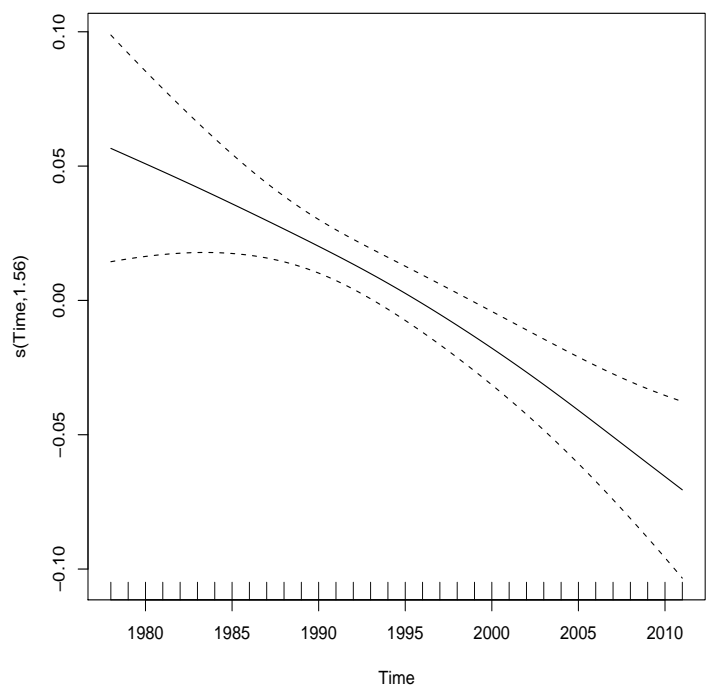

Figure 12: Smooth term for Portugal.

\begin{tabular}{c|ccc} 
& Coeff. & $\begin{array}{c}\text { Std. error \& } \\
\text { (t-stat) }\end{array}$ & $\operatorname{Pr}(>\mathbf{t})$ \\
\hline Const. & -0.10 & $0.023(-4.14)$ & 0.0005 \\
$s(t-1)$ & 0.25 & $0.168(1.50)$ & 0.147 \\
$b(t-1)$ & 0.15 & $0.047(3.26)$ & 0.004 \\
$Y G a p(t)$ & 0.60 & $0.187(3.21)$ & 0.004 \\
$G G a p(t)$ & -0.35 & $0.081(-4.31)$ & 0.0003 \\
\hline $\operatorname{sm}(\mathrm{t})$ & edf & $\mathrm{F}$ & $\mathrm{p}$-val. \\
by $b(t-1)$ & 5.65 & 3.91 & 0.005 \\
\hline & $R^{2}(\operatorname{adj}): 0.93$ & BG: 2.85
\end{tabular}

Table 7: Estimation results Spain.

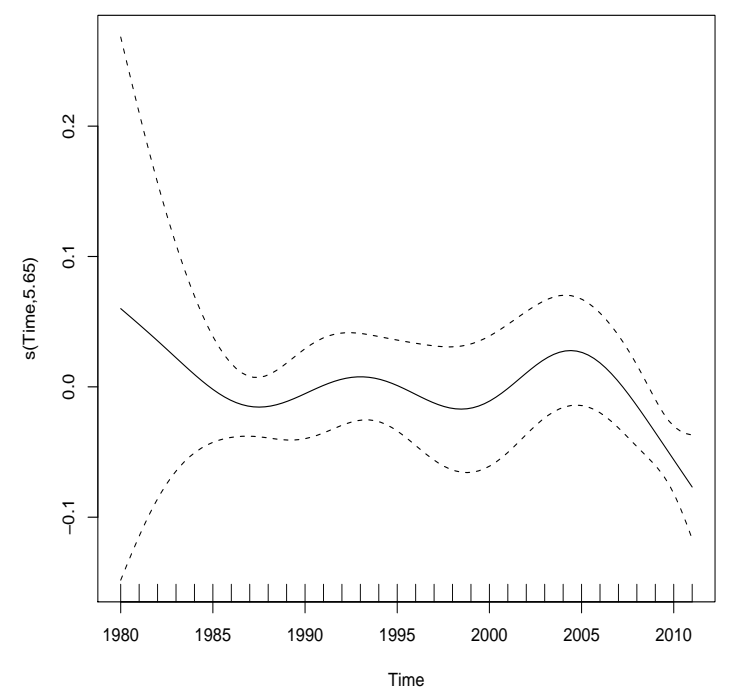

Figure 13: Smooth term for Spain.

Obviously, there is hardly any change compared to the results presented in tables 2 and 3. Here, also the positive and significant reaction coefficients suggest sustainable fiscal policies for both economies, Portugal and Spain. The deviations in the plots 12 and 13 mainly reveal a similar pattern than those in figures 6 and 7 above. 